in euthymic patients with primary affective illness. Science 208:200.

Sitaram N, Gillin JC, Bunney WE Jr (1984): Cholinergic and catecholaminergic receptor sensitivity in affective illness: Strategy and theory. In Post RM, Ballenger JC (eds), Neurobiology of Mood Disorders. Baltimore: Williams \& Wilkins, p 629.
Spitzer RL, Endicott J, Robins E (1978): Research Diagnostic Criteria (RDC) for a Selected Group of Functional Disorders, 3rd ed. New York: New York State Psychiatric Institute.

Zandberg P, DeJong W (1977): Localization of catecholaminergic receptor sites in the nucleus tractus solitarii involved in the regulation of arterial blood pressure. Prog Brain Res 47:117.

\title{
Clinical Correlates of Sleep Onset REM Periods in Depression
}

\author{
Anand Kumar, James E. Shipley, Alan S. Eiser, Michael Feinberg, \\ Pam Flegel, Leon Grunhaus, and Roger F. Haskett
}

\section{Introduction}

A shortened rapid eye movement (REM) latency (RL; interval between sleep onset and the first REM sleep episode) is considered to represent a biological marker of primary depression (Kupfer 1976). The distribution of RL in primary depression has been studied, but contradictory results have been reported (Schulz et al. 1979; Coble et al. 1981; Ansseau et al. 1984; Kupfer et al. 1986). A markedly shortened RL, or sleeponset REM period (SOREM), is usually defined as the appearance of REM sleep within 10-15 min of sleep onset (Carskadon 1976; Schulz and Lund 1985). Reports on the clinical characteristics of depressed patients with SOREM are inconsistent (Coble et al. 1981; Ansseau et al.

\footnotetext{
From the Clinical Studies and Sleep/Depression Units, University of Michigan Medical Center, Ann Arbor, MI

Supported in part by NIH Grants MH28294 and MH39593 and by the University of Michigan, Mental Health Research institute.

Address reprint requests to Dr. Anand Kumar, RM 12S, 207, Building 10, National Institute on Aging, National Institutes of Health, Bethesda, MD 20892.

Received June 24, 1986: revised April 23, 1987
}

1984; Kupfer et al. 1986). Because of these disagreements on SOREM and RL distribution in depression, we undertook a study of the distribution of RL in a sample of inpatient depressives and of the clinical characteristics of subjects with SOREM.

\section{Methods}

Our patient sample for this study consisted of 62 subjects diagnosed using the Schedule for Affective Disorders and Schizophrenia/Research Diagnostic Criteria (SADS/RDC) (Spitzer and Endicott 1977; Spitzer et al. 1978) as having major depressive disorder-definite, with a Hamilton Rating Scale of Depression (HRSD, 17item scale) score of 15 or greater. All of our subjects were inpatients on the Clinical Studies Unit for Affective Disorders (CSU) at the University of Michigan, Ann Arbor, MI. Subjects went through the standard CSU protocol comprising: (1) a 2-week drug-free period, (2) complete blood count (CBC), differential, thyroid 
function tests, electrolytes, $B_{12}$, folate, and VDRL, (3) chest and skull X-rays, and (4) comprehensive medical and neurological exam.

Two consecutive nights of electroencephalogram-recorded (EEG) sleep were completed after a minimum 2-week drug-free period with subjects sleeping in their own hospital beds. Placement of electrodes and scoring was done according to the method of Rechtschaffen and Kales (1968). Sleep onset was defined by the first minute of Stage 2 sleep, followed by at least $10 \mathrm{~min}$ of Stage 2 sleep, interrupted by no more than 2 min of awake or Stage 1. RL was defined as the time between sleep onset and the first REM period (minimum duration: $3 \mathrm{~min}$ ) minus any intervening awake time. Subjects received a weekly rating on the HRSD and a clinical questionnaire (Current Status Questionnaire), which the treating physician completed every week. Patients completed the Carroll selfrating scale of depression weekly (Feinberg et al. 1981). Clinical response was stratified according to the Pittsburgh criteria (cf., Shipley et al. 1985), i.e., subjects were considered to be responders if their HRSD score at discharge was $<10$ and at least $40 \%$ reduced from their admission score, were considered nonresponders if their discharge HRSD score was $\geqq 10$ and showed a reduction of $\leqq 50 \%$ of admission HRSD score, and were indeterminate if they fulfilled neither criteria.

\section{Results}

\section{RL Distribution}

When the data for RLs from nights 1 and 2 were pooled ( $\mathrm{n}=124$ nights), a bimodal distribution was obtained with peaks occurring between 0

Figure 1. The distribution of REM latency for 124 subject-nights of EEG sleep recording. The distribution of REM latency is bimodal, with peaks occurring between 0 and $10 \mathrm{~min}$ and between 40 and $60 \mathrm{~min}$.

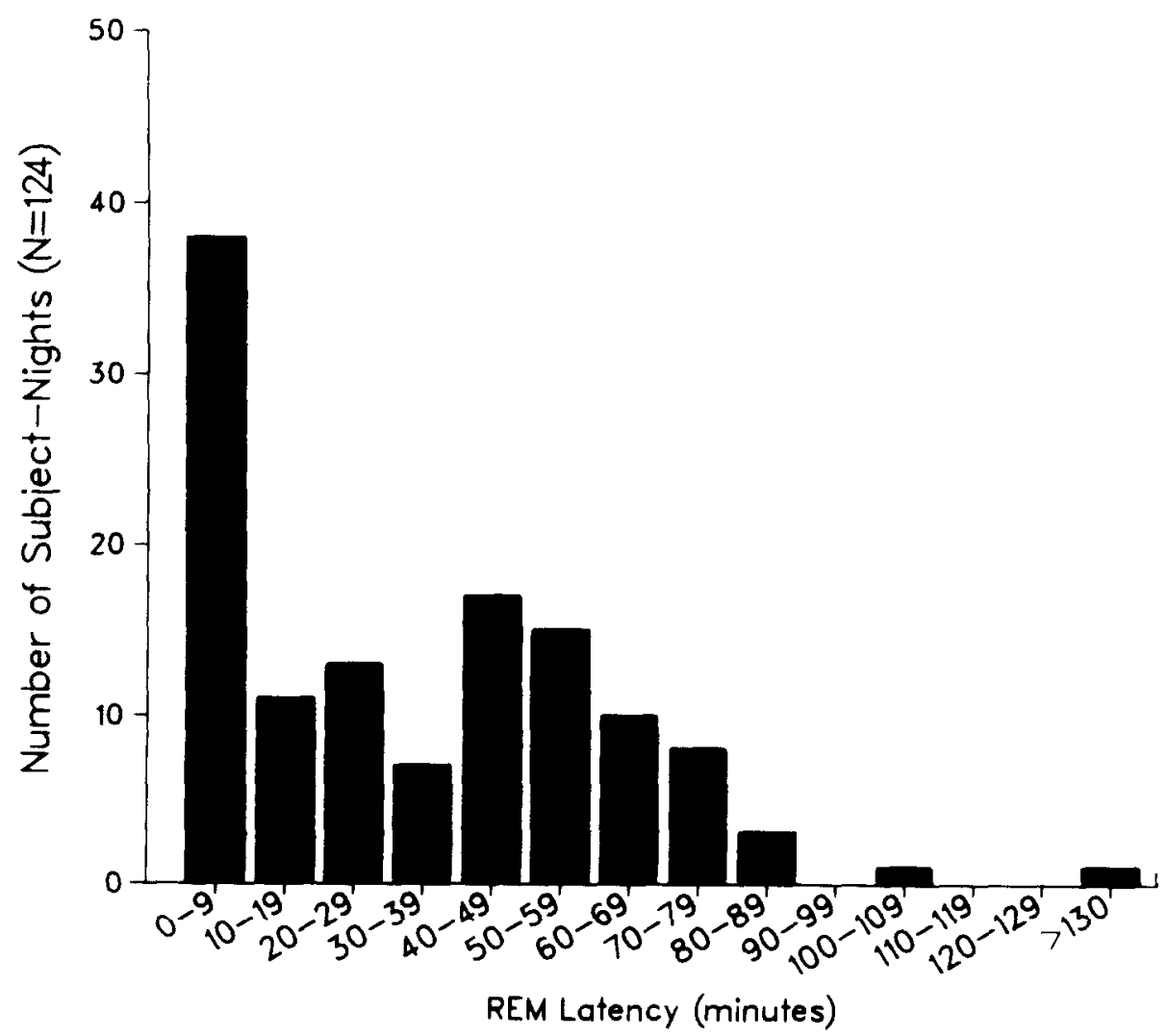


10 and 40-60 min, respectively (Figure 1). Thirty percent of the recordings fell between 0 and 10 minutes and $25.6 \%$ between 40 and 60 minutes. When the lower of the two recorded RLs was considered for each subject, we found that $42 \%$ of our subjects had at least one SOREM- 10.

\section{Clinical Correlates of SOREM}

As we obtained 2 nights of EEG sleep recording on our subjects, the lower of the two RLs was used to divide our patient sample into three groups, as originally described by Ansseau et al. (1984), to examine clinical correlates of SOREM: (Group 1) patients exhibiting at least 1 night of RL $<10 \mathrm{~min}$, or SOREM-10 yielding an $n=26$; (Group 2) patients exhibiting no SOREM-10, but having at least one RL between 10 and $19 \mathrm{~min}$ (SOREM-20), yielding an $\mathrm{n}=$ 6 ; and (Group 3 ) those with both RLs $\geqq 20 \mathrm{~min}$, yielding an $n=30$. RDC diagnostic categories, demographic features, and clinical responsc of the RL groups were analyzed using the chi-square statistic. One-way Analysis of Variance (ANOVA) was used to compare parametric information (age, HRSD scores, age at first onset, etc.).

Subjects with SOREM-10 differed demographically from the other groups in that they were older at the time of study and also at the onset of the first depressive episode (Table 1, $p<0.03)$. Attempted analysis of covariance on $\mathrm{RL}$ for the three RL groups using age as a covariate demonstrated that age was not a significant covariate $(p=0.39)$ in this sample. The three groups did not differ significantly in any of the RDC diagnostic categories or in terms of treatment response at discharge or family history of mania or depression. Subjects with SOREM10 had a longer hospital stay and more frequently had a family history of suicide than those without SOREM-10 $(p<0.03)$. In the entire sample of 62 subjects, 7 subjects received electroconvulsive therapy (ECT). Six of the seven were in the SOREM-10 group, and the other belonged to the SOREM-20 category (Table 1,

Table 1. Clinical and Demographic Features of the Three REM Latency Groups

\begin{tabular}{|c|c|c|c|c|c|}
\hline $\begin{array}{c}\text { Clinical and demographic } \\
\text { characteristics }\end{array}$ & $\begin{array}{c}\text { SOREM-10 } \\
\mathrm{n}=26 \\
\text { (mean } \pm \mathrm{SD})\end{array}$ & $\begin{array}{c}\text { SOREM-20 } \\
\mathrm{n}=6 \\
\text { (mean } \pm \mathrm{SD} \text { ) }\end{array}$ & $\begin{array}{c}\text { Non-SOREM } \\
n=30 \\
\text { (mean } \pm S D \text { ) }\end{array}$ & $F$ or $\chi^{2}$ & $p<$ \\
\hline Age & $55.0 \pm 11.4$ & $42.5 \pm 12.4$ & $40.3 \pm 11.9$ & 8.02 & 0.001 \\
\hline Age of first episode & $39.8 \pm 11.6$ & $32.6 \pm 13.7$ & $29.5 \pm 16.0$ & 3.00 & $0.06^{a}$ \\
\hline Number of prior episodes & $3.7 \pm 2.8$ & $2.5 \pm 3.0$ & $3.0 \pm 3.0$ & 0.64 & NS \\
\hline $\begin{array}{l}\text { Length of hospital stay } \\
\text { in days }\end{array}$ & $80.7 \pm 40.5$ & $55.5 \pm 21.5$ & $59.4 \pm 22.2$ & 3.71 & 0.03 \\
\hline HRSD scores & $23.8 \pm 6.1$ & $21.9 \pm 2.7$ & $21.8 \pm 4.8$ & 1.08 & NS \\
\hline Carroll scores & $33.5 \pm 8.0$ & $33.3 \pm 6.5$ & $28.2 \pm 9.2$ & 2.67 & $0.08^{a}$ \\
\hline \multicolumn{6}{|l|}{ Sex } \\
\hline Male & 9 & 1 & 9 & & \\
\hline Female & 17 & 5 & 21 & 0.75 & NS \\
\hline $\begin{array}{l}\text { Positive family history } \\
\text { of suicide }\end{array}$ & $8 / 26$ & $2 / 6$ & $2 / 26$ & 4.87 & $0.03^{b}$ \\
\hline Number receiving ECT & $6 / 26$ & $1 / 6$ & $0 / 30$ & 7.60 & 0.03 \\
\hline \multicolumn{6}{|l|}{ Bipolarity } \\
\hline UP & 17 & 6 & 19 & & \\
\hline $\mathrm{BP}$ & 9 & 0 & 11 & 3.19 & NS \\
\hline BP-1 & 6 & 0 & 3 & & \\
\hline $\mathrm{BP}-2$ & 3 & 0 & 8 & 3.10 & NS \\
\hline \multicolumn{6}{|l|}{ Treatment response } \\
\hline Good & 17 & 4 & 18 & 1.08 & NS \\
\hline Poor & 6 & 2 & 9 & & \\
\hline Indeterminate & 3 & 0 & 3 & & \\
\hline
\end{tabular}

aSOREM-10 $>$ non-SOREM by follow-up comparison, $p<0.03$.

${ }^{b}$ For $2 \times 2$ comparison of SOREM-10 with non-SOREM group. 
$p<0.03$ ). The SOREM-10 group was not more severely depressed by HRSD than the other RL. categories. When Carroll self-rating scores of depression were considered, however, the SOREM-10 group had higher scores than the nonSOREM group (Table $1, p<0.03$ ).

\section{Discussion}

Our data show a clear bimodal distribution of RL, with peaks occurring between $0-10$ and 40 $60 \mathrm{~min}$. Earlier reports on RL distribution in depressives ranged from bimodal (Schulz et al. 1979; Coble et al. 1981) to unimodal (Ansseau et al. 1984). Forty-two percent of our patients exhibited at least 1 night of SOREM-10, and thus, our results confirm earlier reports that SOREM-10 occurs in a significant proportion of inpatient depressives (Schulz et al. 1979; Coble et al. 1981).

Samples with a high mean age show a single RL peak and a high prevalence of SOREM. For example, Reynolds et al. (1985), whose sample had a mean age of 69.9 years, found $42 \%$ of all nights with SOREM-10, whereas $30 \%$ was found in our more middle-aged sample. A sample with a younger mean age ( 36.4 years) than our sample had only $8 \%$ of nights with SORFM10 (Ansseau et al. 1984). In accord with this, our patients exhibiting SOREM-10 were older both at the time of study and during the first episode of depression than those without SOREM. This is consistent with reports of an agerelated decrease in RL in normals, and even more markedly in depressives (Ulrich et al. 1980; Reynolds et al, 1985). Thus, age appears to at least partially account for the distribution of RL in depression. Other factors appearing to favor the presence of SOREM include inpatient status (Rush et al. 1982; Kupfer et al. 1986) and psychoticism, agitation, or retardation (Kupfer et al. 1986; Thase et al. 1986).

An inverse correlation between RL and severity of depression has been suggested (Spiker et al. 1978), but our subjects with SOREM-10 did not differ from non-SOREM patients in either their HRSD scores or in any of the RDC diagnostic categories. However, they had higher
Carroll self-rating scores for depression than those without SOREM-10. Concerning associations of other clinical features with SOREM, with clinicians blind to sleep study results, six of the seven subjects who later received ECT had SOREM-10. The RL of the seventh subject was also less than $20 \mathrm{~min}$. Thus, no non-SOREM patients received ECT. Subjects with SORFM10 required hospitalization for 3 weeks longer than those without SOREM. In sum, SOREM appears to be associated with a more severe illness.

Our findings should encourage continued study of SOREM. It would be of interest to examine the relationship of RL and SOREM to other psychobiological mcasures, such as hypothalamic-pituitary-adrenal axis function (Rush et al. 1982).

\section{References}

Ansseau M, Kupfer DJ, Reynolds C, McEachran AB (1984): REM latency distribution in major depression: Clinical characteristics associated with sleep onset REM periods. Biol Psychiatry 19:1651-1666.

Carskadon M (1976): The role of sleep onset REM periods in narcolepsy. In Guilleminault C, Dement WC, Passouant P (eds), Narcolepsy. New York: Spectrum Publications, pp 499-519.

Coble PA, Kupfer DJ, Shaw DH (1981): Distribution of REM latency in depression. Biol Psychiatry 16:453-466.

Feinberg M, Carroll B, Smouse PE, Rawson SG (1981): The Carroll rating scale for depression III. Comparison with other rating instruments. $\mathrm{BrJ}$ Psychiatry 138:205-209.

Kupfer DJ (1976). REM latency. A psychobiological marker for primary depressive disease. Biol Psychiatry 11:159-174.

Kupfer DJ, Reynolds CF, Grochocinski VJ, Ulrich R, McEachran A (1986): Aspects of short REM latency in affective states: A revisit. Psychiarry Res 17:49-59.

Rechtschaffen A, Kales A (1968): A Manual of Standardized Terminology, Techniques and Scoring System for Sleep Stages of Human Subjects. Washington, DC: Public Health Service, US Government Printing Office.

Reynolds C, Kupfer DJ, Taska L, Hock CC, Spiker D, Sewitch DE, Zimmer B, Marin RS, Nelson 
JP, Martin D, Moryez R (1985): EEG sleep in elderly depressed, demented and healthy subjects. Biol Psychiatry 20:431-442.

Rush AJ, Giles DE, Roffwarg H, Parker CR (1982): Sleep EEG and Dexamethasone Suppression Test findings in outpatients with unipolar major depressive disorders. Biol Psychiatry 17:327341.

Schulz H, Lund R (1985): On the origin of early REM episodes in the sleep of depressed patients: A comparison of three hypotheses. Psychiatry Res 16:65-77.

Schulz M, Lund R, Cording C, Dirlich G (1979): Bimodal distribution of REM sleep latencies in depression. Biol Psychiatry 14:595-600.

Shipley JE, Kupfer DJ, Griffin S, Dealy R, Coble P, McEachran A, Grochocinski V, Ulrich R, Perel J (1985): Comparison of effects of desipramine and amitriptyline on EEG sleep of depressed patients. Psychopharmacology 85:14-22.

Spiker DG, Coble PA, Cofsky J, Foster FG, Kupfer DJ (1978): EEG sleep and severity of depression. Biol Psychiatry 13:485-488.

Spitzer RL, Endicott J (1977): Schedule for Affective Disorders and Schizophrenia (SADS), 3rd ed. New York: Biometrics Research, New York State Psychiatry Institute.

Spitzer RL, Endicott J, Robins E (1978): Research Diagnostic Criteria: Rationale and reliability. Arch Gen Psychiatry 38:773-782.

Thase ME, Kupfer DJ, Ulrich RF (1986): EEG sleep in psychotic depression--A valid subtype? Arch Gen Psychiatry 43:886-893.

Ulrich RF, Shaw DH, Kupfer DJ (1980): Effects of aging on EEG sleep in depression. Sleep 3:3140.

\title{
Taste and Smell Perception in Depression
}

\author{
Jay D. Amsterdam, R. Gregg Settle, Richard L. Doty, \\ Ellen Abelman, and Andrew Winokur
}

\section{Introduction}

In addition to the disorders of appetite, weight maintenance, or hyperphagia encountered in depressive illness (Hopkinson 1981), some depressed patients may also complain specifically of a diminished ability to taste and to enjoy food,

From the Depression Research Unit (J.D.A., E.A., A.W.), Department of Psychiatry, and the Smell and Taste Center, Department of Otorhinolaryngology and Human Communication (R.G.S., R.L.D.), School of Medicine. University of Pennsylvania, Philadelphia; and the Medical Research Service, Veterans Administration Medical Center (R.G.S.), Philadelphia, PA.

Supported in part by the Jack Warsaw Fund for Research in Biological Psychiatry (J.D.A.) NINCDS Grant NS 16365 (R.G.S.. R.C.D.) and NIMH Research Scientist Award MH 00044 (A.W.).

Address reprint requests to Dr. J.D. Amsterdam, Department of Psychiatry, Hospital of the University of Pennsylvania, 36th and Spruce Streets, Philadelphia, PA 19104-4283.

Received December 3, 1986; revised May 26, 1987. and some report a craving for sweets (Steiner et al. 1969; Harris et al. 1984). Steiner et al. (1969) long ago reported that sucrose taste recognition thresholds were significantly elevated in depressives. We undertook to repeat these observations, and because complaints of taste alteration sometimes arise from olfactory deficiency (cf., Doty and Kimmelman 1986), we also studied smell perception.

\section{Experiment 1: Sucrose \\ Taste Perception}

\section{Methods}

Subjects. Taste intensity and pleasantness ratings were obtained from 36 depressed patients [ 17 men with a mean age ( \pm SD) of $47 \pm 14$ 